\title{
Local Measurement of Reaction Kinetics Using in situ Transmission Electron Microscopy
}

\author{
Renu Sharma and Peter Crozier \\ Center for Solid State Science, Arizona State University, Tempe, AZ 85287-1704
}

In solids, reaction rates and corresponding reaction mechanisms may be strongly influenced by nanostructural features such as defects, second phase precipitates and surface and interface properties. In order to correlate local changes in reaction rates to the microstructure, data must be obtained from the same sample regions. In situ microscopy is an excellent technique for correlating reaction kinetics with microstructure. In the TEM, the microstructure and chemical changes can be characterized using imaging, diffraction and spectroscopy signals. The kinetics can be determined by monitoring changes in the same signals. The time resolution of these kinetic measurements is limited only by signal-to-noise and detector technologies. We have developed several controlled atmosphere microscopes for studying local kinetics in gas-solid reactions. In such instruments, we are able to reveal fluctuations in local kinetics and correlate them with inhomogeneities in the solid. Here we illustrate this approach by application of the technique to a range of different problems in materials and solid-state chemistry.

The first example (Figure 1) demonstrates nucleation and growth of $\mathrm{Cu}$ particles during the nitridation of $\mathrm{Cu}$ - $\mathrm{Ti}$ thin films when heated up to $420^{\circ} \mathrm{C}$ in 3 Torr of $\mathrm{NH}_{3}$. $\mathrm{Cu}$ is depleted from the matrix during nitridation and grows into large particles. Most of the $\mathrm{Cu}$ particles (marked $\mathrm{A}, \mathrm{C}$ and E) grow as circular particles but two other particles (marked B and D) have different growth rates in two directions. This is due to variations in the growth rate of different crystallographic planes. Temperature resolved data was used to derive the kinetics of the reaction. The nitridation temperature for these samples was determined by electron diffraction and was found to reduce with increasing concentration of $\mathrm{Cu}$ in the thin films (Figure 2). Similar measurements were made for $\mathrm{Cu}-\mathrm{Cr}$ thin films. The nucleation was dependent on the chemical reaction rate while the growth was controlled by $\mathrm{Cu}$ diffusion rates.

Growth rates for $\mathrm{Au}$ particles have also been measured from time resolved video sequences recorded during chemical vapor deposition (CVD) on clean Si $\{100\}$ surfaces. ${ }^{1}$ The ion milled Si samples were heated at different temperatures in $10^{-3}$ Torr of ethyl (trimethylphosphine) gold (I) $\left(\mathrm{EtAu}\left(\mathrm{PMe}_{3}\right)\right)$ and deposition was performed both with and without the electron irradiation. While a simple linear relationship could be observed between the growth rate and temperature (Figure 3) for depositions without the electron irradiation, data recorded during electron irradiation could not be fitted to a linear equation indicating a more complex reaction mechanism.

We have developed a method to obtain the local oxidation state of $\mathrm{Ce}$ in complex oxides during redox reactions ${ }^{2}$. The oxide compositions and surface areas were found to play important roles in the redox activity of $\mathrm{Ce}$ containing catalysts. The $\mathrm{Ce}$ oxidation is obtained by monitoring the change in white-line ratios $\left(\mathrm{M}_{45}\right)$ in the electron energy-loss spectrum during redox reactions. This technique can be used to obtain local kinetics during redox reactions in many transition metal systems. 
In situ microscopy can provide direct information on the kinetics and dynamic mechanisms of polymerization processes. We have studied the initial stages of nanoscale polypropylene (PP) growth during gas phase Ze igler-Natta polymerization. Polymerizations were run in situ under $\mathrm{C}_{3} \mathrm{H}_{6}$ pressures $\sim 1$ Torr and revealed growth of non-uniform PP layers over areas $\sim 100 \mathrm{~nm}$ in size with diffuse interfaces between adjacent globules. Local kinetics demonstrated a linear behav ior with a growth rate of $0.16-0.23 \mathrm{~nm} / \mathrm{s}$ implying that there is no significant diffusion barrier for $\mathrm{C}_{3} \mathrm{H}_{6}$ through PP up to $140 \mathrm{~nm}$. Active sites are probably located at the interface between the PP layer and the catalyst. The measured growth rate is 6 order s of magnitude lower than a surface collision model would predict suggesting that there is a slow rate -determining step in the polymerization process.

Figure 2
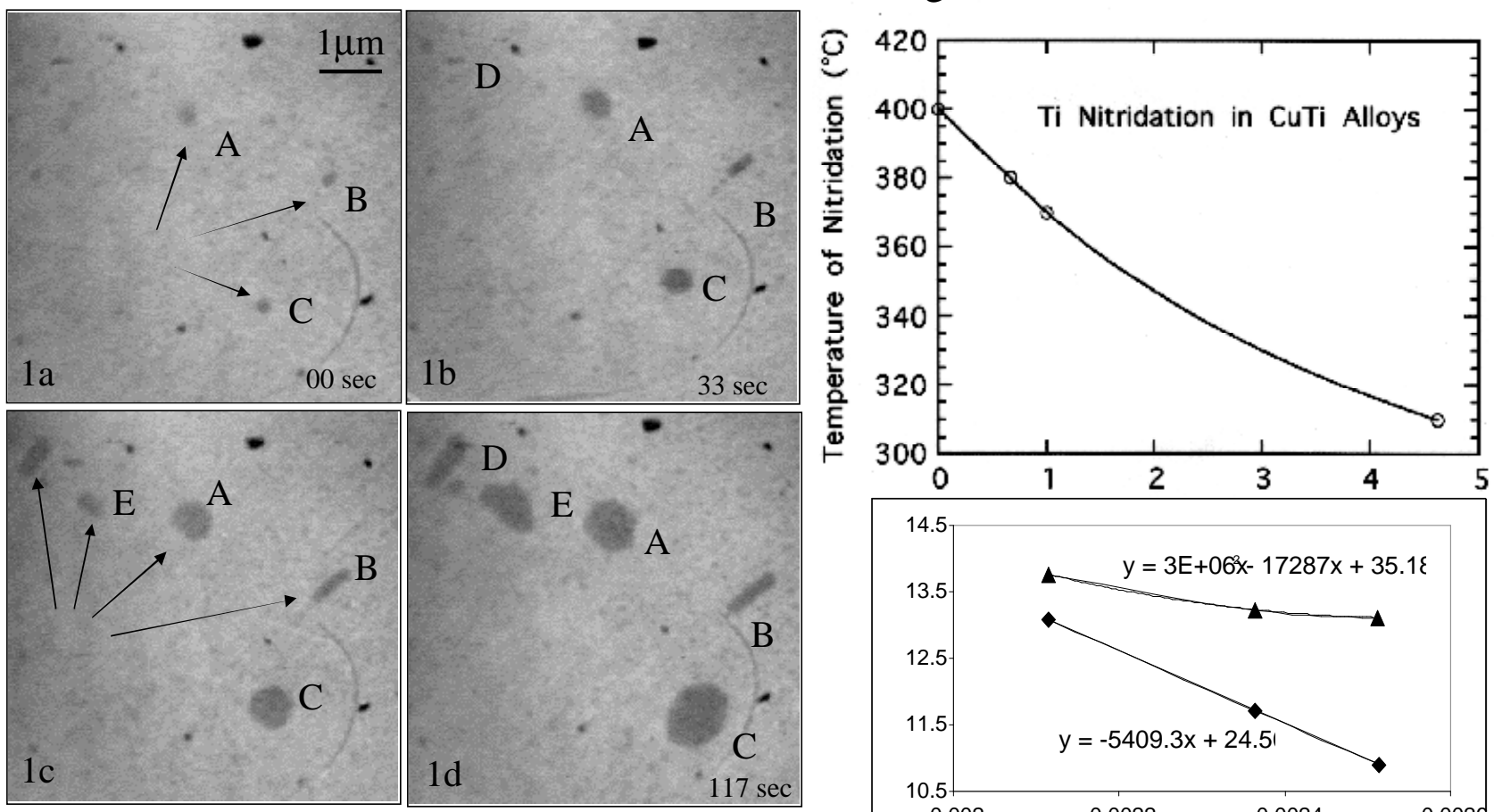

Figure 3 $\rightarrow$

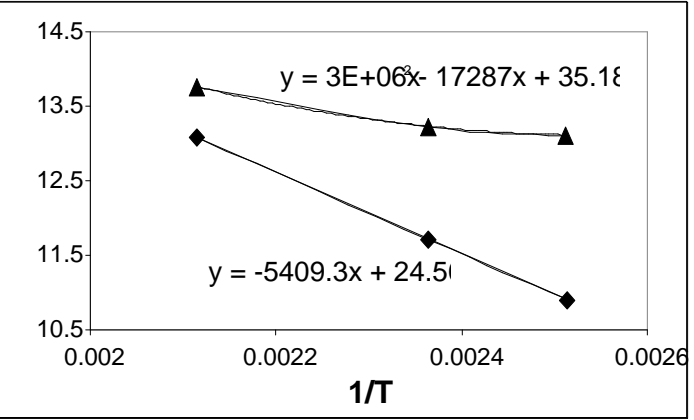

Figure 1a-d. Time resolved low-magnification images recorded at $420^{\circ} \mathrm{C}$ in 3 Torr of $\mathrm{NH}_{3}$ showing the nucleation and growth of $\mathrm{Cu}$ particles during the nitridation of $\mathrm{Ti}$ in $\mathrm{Cu} / \mathrm{Ti}$ thin films. Figure 2. The nitridation temperature reduced with increasing $\mathrm{Cu}$ content of the matrix.

Figure 3. Arrhenius plots of $\log _{10}$ (growth rates (atoms $/ \mathrm{cm}^{2} / \mathrm{sec}$ )) of $\mathrm{Au}$ particles with electron irradiation (triangles) and without irradiation (diamonds).

References

1. Drucker et al, J. Appl. Phys. 77 (1995) 2846.

2. Sharma and Crozier, Microscopy and Microanalysis 2002 (these proceedings)

3. Oleshko et al, J. of Electron Microscopy, 2002 (in press) 